\title{
WNT4, RSPO1, and FOXL2 in Sex Development
}

\author{
Anna Biason-Lauber, M.D. ${ }^{1}$ \\ ${ }^{1}$ Department of Medicine, University of Fribourg, Fribourg, \\ Switzerland (e-mail: anna.lauber@unifr.ch)
}

\begin{abstract}
The idea that the female sexual development happens by default was born in the middle of the last century after Jost performed his innovative experiments to study the bases of differentiation of the reproductive tract and found that the female reproductive tract develops even in the absence of any gonad. The term default (passive) attributed to the whole female developmental pathway, therefore, established itself, even if it was not originally so intended. However, recent developments have demonstrated that ovarian development is an active process. Wingless type MMTV integration site family, member 4 (WNT4), one of a few factors with a demonstrated function in the ovarian-determination pathway, has been found to be involved in sexual differentiation by suppressing male sexual differentiation, promoting Müllerian duct differentiation, and maintaining oocyte health. WNT4 expression in the ovary seems to be regulated by R-spondin 1 (RSPO1), a thrombospondin family member protein. The role and interactions of WNT4, RSPO1, and other factors such as forkhead transcription factor 2 in ovarian development and function will be discussed.
\end{abstract}

\section{Physiology of Sex Development}

In sex development we can distinguish two different processes: sex determination, which is the developmental decision that directs the undifferentiated embryo into a sexually dimorphic individual, and sex differentiation, which takes place once the sex determination decision has been made through factors produced by the gonads that determine the development of the phenotypic sex. At the beginning of gestation (first and second weeks), embryos of the two sexes differ only in their karyotypes. Starting at week 3 specific genes lead to the differentiation of the gonads that, in turn, produce hormones inducing anatomical and psychological differences, leading to behavioral differences that are ultimately influenced by the social environment. At gestational weeks 6 to 7 the paramesonephric duct (Müllerian duct) develops next to the mesonephric duct (wolffian duct). If testes develop and secrete testosterone, the mesonephric duct increases in size and differentiates into epididymis, vas deferens, and prostate. A glycoprotein secreted from the Sertoli cells, known as anti-Müllerian hormone or Müllerian inhibiting substance, results in Müllerian duct regression. If testes do not develop, the mesonephric duct does not grow and eventually degenerates, whereas the paramesonephric duct proliferates and the fallopian tube, uterus, and upper third of the vagina develop.

In mammals, including humans, the differentiation of the gonads is the turning point of this whole process. The classical textbook theory says that in the presence of the sex-determining region on the Y-chromosome (SRY), the default female pathway of sex determination will be inhibited and therefore testes will be formed. In the XX individual because of the absence of SRY no inhibition of the default program will take place and ovaries will develop. Ovarian-determining factors might help the process of differentiation. However, these factors are not yet fully determined. The second model called the Z-factor theory was proposed to explain the cases where $\mathrm{XX}$ individuals develop testes in the absence of SRY. According to this theory, the XX gonad expresses a factor that has both antitestis and pro-ovary function. SRY in XY individuals acts as an inhibitor of the Z-factor to lift the block on the male pathway. In this case, the bipotential gonad will differentiate into a testis. ${ }^{1}$

It seems that SRY acts on a single gene, SRY-box 9 (SOX9), the expression of which is then rapidly reinforced by positive 


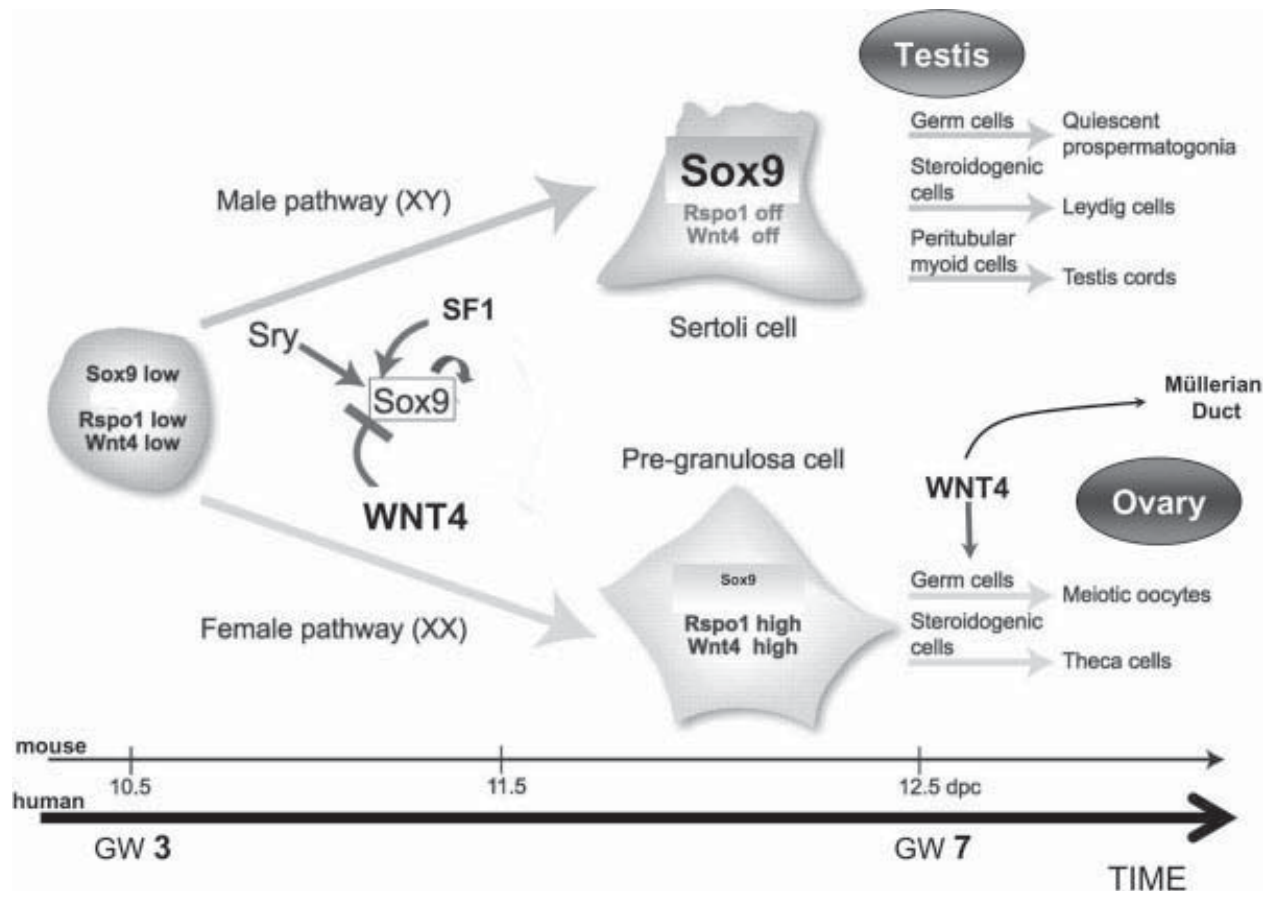

Figure 1 Somatic sex determination cascade based on studies in mice. The gonadal bipotential cells (green) into male Sertoli cells (blue) or female pregranulosa cells (pink). The main players and their changes in gene expression driving supporting cell differentiation and the downstream sexual differentiation of other gonadal cell types are indicated. Abbreviations: Rspo1, R-spondin 1; SRY, sex determining region Y; Sox9, SRY-box 9; Wnt4, wingless-type MMMTV integration site family member 4. (Derived from Kocer A, Reichmann J, Best D, Adams IR. Germ cell sex determination in mammals. Mol Hum Reprod 2009;15(4):205-213. ${ }^{62}$ )

regulatory loops. SOX9 then drives Sertoli cell formation and, therefore, testis differentiation. If SRY is absent, fails to act in time, or SOX9 is otherwise silenced, the follicle cell, chiefly pregranulosa cells, develops and ovary ensues, with $\beta$-catenin being one of the crucial components driving this process. In simple terms testis formation requires SOX9 expression to be high (on), while ovary development needs SOX9 to be low (off) ( - Fig. 1).

Although factors involved in male sexual differentiation have been well studied, the pathways regulating female sexual differentiation remain incompletely defined. Until recently, no genes had been identified to play a similar role in ovarian development as was shown for SRY or SOX9 gene in testicular development. Wingless type MMTV integration site family, member 4(WNT4), R-spondin1 (RSPO1), and forkhead transcription factor 2 (FOXL2) are some of the few factors with a demonstrated function in the ovarian-determination pathway. They suppress male sexual differentiation mainly by restraining SOX9 expression and promote female development by sustaining Müllerian duct differentiation and oocyte health (see below).

\section{WNT4}

WNT4 is a member of the WNT family of secreted molecules that function in a paracrine manner to affect several developmental changes. WNT proteins bind to members of the frizzled (FZ) family of cell-surface receptors and possibly to the single-pass transmembrane protein LDL-receptor-related proteins 5 and 6 (LRP5 and LRP6). ${ }^{2}$ The binding of WNT to FZ leads to activation of the phosphoprotein dishevelled (DSH). The activation and membrane recruitment of DSH probably recruits and the destruction complex (including adenomatous polyposis of the colon (APC), casein kinase 1 , and glycogen synthase kinase 3 [GSK3]) to the plasma membrane, where AXIN directly binds to the cytoplasmic tail of LRP5/6. AXIN is then degraded, which decreases $\beta$-catenin degradation. The activation of DSH also leads to the inhibition of GSK3, which further reduces phosphorylation and degradation of $\beta$-catenin with consequent $\beta$-catenin-dependent induction of Wnt-responsive genes. ${ }^{3}$ Wnt proteins can also signal via a $\beta$-catenin independent noncanonical pathway involving protein kinase $\mathrm{C}$ and c-jun $\mathrm{NH} 2$-terminal kinase. ${ }^{4}$ (Readers interested in learning more about WNT proteins should visit the informative site http://www.stanford.edu/ $\sim$ rnusse/wntwindow.html.)

Wnt4 is produced in mouse ovarian somatic cells (pregranulosa cells) and oocytes. In humans, WNT4 is expressed in fetal granulosa cells at early stages with increasing expression in oocytes in primordial follicles, with a peak at mid and late gestation, when the follicles are formed. ${ }^{5}$ After birth, WNT4 expression was detectable in oocytes and granulosa cells, especially in primary and secondary follicles, supporting the idea that WNT4 is a "pro-ovary" factor. Wnt4 upregulates dosage sensitive adrenal hypoplasia on chromosome X, gene 1 (Dax 1$),{ }^{6}$ a gene known to antagonize the nuclear-receptor steroid factor 1 , and thereby inhibits steroidogenic enzymes. Wnt4 collaborates with Rspo1 to stabilize $\beta$-catenin that, in turn, works to limit the expression of the male-specific gene Sox9, thus exerting an "antitestis" effect. Vainio et al $^{7}$ observed 
in Wnt4-deficient mice that gonadal development and steroidogenic function were affected exclusively in female Wnt4knockout mice, whereas both male and female mice had similar defects in kidney development and adrenal function. Wnt4-knockout female mice were masculinized, as demonstrated by the absence of Müllerian ducts and the presence of wolffian ducts, and expressed the steroidogenic enzymes $3 \beta$ hydroxysteroid dehydrogenase and $17 \alpha$-hydroxylase, which are required for the production of testosterone and are normally suppressed in the developing female ovary. Furthermore, female mice lacking Wnt4 and follicostatin have in their gonads a testis-specific artery, the coelomic vessel, which plays a critical role in patterning of testis cords and later in hormone transport. $^{8}$ On the other hand, the ovaries of the Wnt4knockout mice also had less oocytes, suggesting a role of Wnt4 in the life of female germ cells. This function is crucial for the organization of ovarian structure, because female germ cells have a central role in this process and in maintenance of the ovary, as demonstrated by the fact that when oocytes are either absent ${ }^{9}$ or lost after follicle formation ${ }^{10}$ ovarian follicles never form or degenerate subsequently. In contrast, testis development proceeds in the absence of germ cells. WNT4 appears to maintain oocyte viability once germ cells have reached their final destination in the gonad.

Naillat et $\mathrm{al}^{11}$ demonstrated in mice that somatic Wnt signaling was crucial for the control of female germ line development. Wnt4 maintained germ cell cysts and early follicular gene expression and provided a female pattern of $\mathrm{E}$ cadherin and $\beta$-catenin expression within the germ cells. Reintroduction of a Wnt4 signal to the partially masculinized embryonic ovary rescued the female property to a certain degree. Wnt 4 deficiency allowed only $20 \%$ of the germ cells to initiate meiosis in the ovary.

Ottolenghi et al ${ }^{12}$ observed formation of testis-like tubules and spermatogonia in the ovaries of Wnt4/Foxl2 doubleknockout XX mice, demonstrating that female sex-determining genes, the putative "ovary organizer," are required to suppress an alternative male fate in the ovary and act as a female equivalent of SRY.

\section{WNT4 and Human Disease}

In humans more copies of WNT4, because of duplication of chromosome 1p31-p35, were found in a patient with ambiguous genitalia, severe hypospadia, fibrous gonads, and remnants of both Müllerian and wolffian ducts, that is, male-tofemale sex reversal. ${ }^{5}$ On the other end of the spectrum, when both copies of the gene are inactive, as in the case of homozygote mutations, a severe clinical entity called the SERKAL syndrome results. ${ }^{13}$ The syndrome was described in three 46, XX fetuses and is characterized by female-to-male sex reversal with ambiguous genitalia, gonadal morphology ranging from ovotestis to normal testis, renal agenesis, adrenal hypoplasia, and pulmonary and cardiac abnormalities. In the middle of such spectrum one might expect to find patients with intermediate defects of sex development. Searches for clinically relevant WNT4 mutations sometimes in large cohorts of these patients were unsuccessful. ${ }^{14} \mathrm{We}$ described a woman with absent Müllerian structures (uterine and fallopian tubes) who had unilateral renal agenesis and clinical signs of androgen excess. Her phenotype resembles that of patients with the Mayer-Rokitansky-Küster-Hauser syndrome and is also strikingly similar to that of Wnt4knockout female mice (-Fig. 2A, B). This constellation of findings prompted us to search for mutations in the WNT4 gene in this patient. Direct sequencing of polymerase chain reaction-amplified exonic fragments revealed a heterozygous mutation leading to an E226G/WT missense exchange in the WNT4 protein. In search for causes of the defective signaling, we found that the E226G mutant protein appears to be trapped inside the cell, ${ }^{15}$ likely because of defective posttranslational lipid modification, necessary for WNT proper function. ${ }^{3}$ Because any generalizations regarding WNT4 role in humans must await the description and characterization of mutations in additional patients, we searched for additional subjects with WNT4 mutations. The recent identification of other women ${ }^{16-18}$ with a similar phenotype and mutations in WNT4 confirmed its role in ovarian and female reproductive tract development in women ( $\mathbf{- F i g}$. 2C). These additional patients also helped to refine the phenotype of WNT4 deficiency in humans. In fact, it appears that the absence of uterus (and not other Müllerian abnormalities) and the androgen excess are the pathognomic signs of WNT4 defects, suggesting that this might be a clinical entity distinct from the classical Mayer-Rokitansky-Küster-Hauser syndrome. The functional studies performed in these cases suggested that the consequences of the present WNT4 mutation range from lack of lipid modification (and probable misfolding), ${ }^{15}$ to misfolding and formation of intractable aggregates, ${ }^{16}$ to defects in receptor binding ${ }^{17,18}$ ( - Fig. 2C). The fact that these patients are heterozygotes and the results of the expression studies suggest that one normal copy of WNT4 is not only inadequate to maintain protein function but is also negatively influenced by the mutant protein (dominant negative effect). Although this is not a classical gene-dosage phenomenon, because the gene copies are the same (except in the duplication case), it is certainly a dosage-sensitive sex-determining process, as Jordan et al already predicted. ${ }^{5}$ In fact, while too much WNT4 activity (duplication) induces feminization of the male (46, XY disorders of sex development [DSD]), too little WNT4 activity (homozygous loss-of-function mutation) induces exactly the opposite; i.e., masculinization of the female (46, XX DSD). Because WNT4 inhibits the male development in the female and males do not need WNT4 for their sex development, ${ }^{6}$ situations between these two extremes are characterized by different degrees of masculinization of the female. Although the presence of negative dominance renders the case arithmetically more complex, the relationship between activity levels and phenotype of WNT4 abnormalities is rather striking and corroborates the idea that sex differentiation is a matter of dosage (-Fig. $\mathbf{3}$ ).

\section{RSP01}

Kamata et $\mathrm{al}^{19}$ identified the mouse Rspo1 gene, which encodes a 265 amino acid sequence with a calculated molecular mass of $29 \mathrm{kD}$. Unlike other secretory proteins of the 

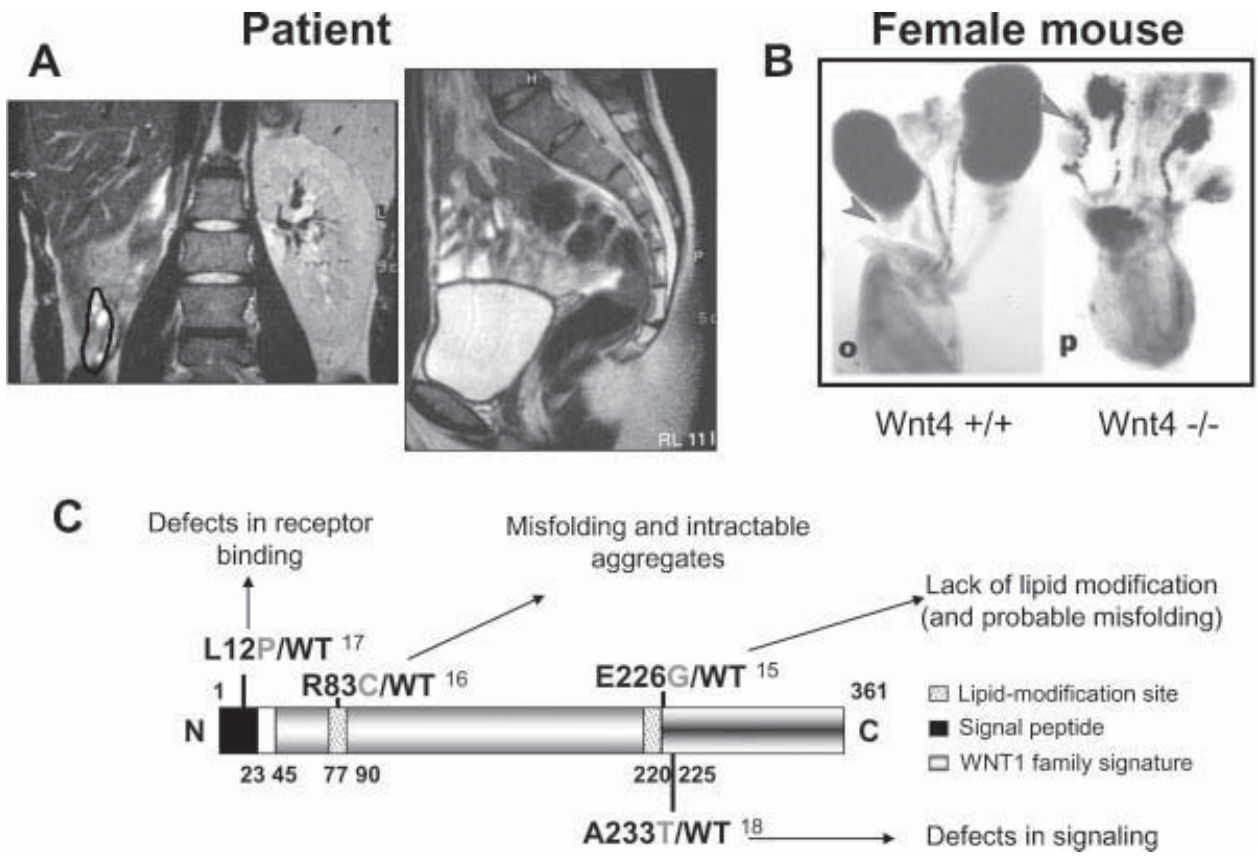

Figure 2 (A) Magnetic resonance imaging of the abdominal cavity of the first WNT4-deficient patient showing lack of uterus and tubes, the renal agenesis, and the ectopic ovary. For comparison, the correspondent structure of wild type (Wnt $4+1+$ ) and female mice lacking Wnt4 (Wnt4 - -) are depicted in panel (B) (from Vainio S, Heikkilä M, Kispert A, Chin N, McMahon AP. Female development in mammals is regulated by Wnt-4 signalling. Nature 1999;397(6718):405-409. ${ }^{6}$ ) (C) Known mutations in WNT4 gene found in women with no uterus and signs of virilization. The functional consequences of the mutations are also reported. Homozygote mutations (not shown) are linked to a more severe entity, called SERKAL syndrome. ${ }^{13}$

thrombospondin family, RSPO contains no apparent secretion cleavage site, but has a putative N-terminal nuclear localization signal. RSPO transcripts were observed mainly in central nervous system (CNS) tissues. Outside the , RSPO transcripts were detected in forelimb buds after 10 days post conception, especially in the body trunk and the proximal posterior part of the anterior limb bud. Kim et al found that human RSPO is expressed in enteroendocrine cells as well as in epithelial cells from various tissues. ${ }^{20}$

In mice, the ovarian phenotype of XX, Rspo $1-/-$ is strikingly similar to that of Wnt $4-/$ - female mice, especially for the formation of coelomic vessels and the presence of

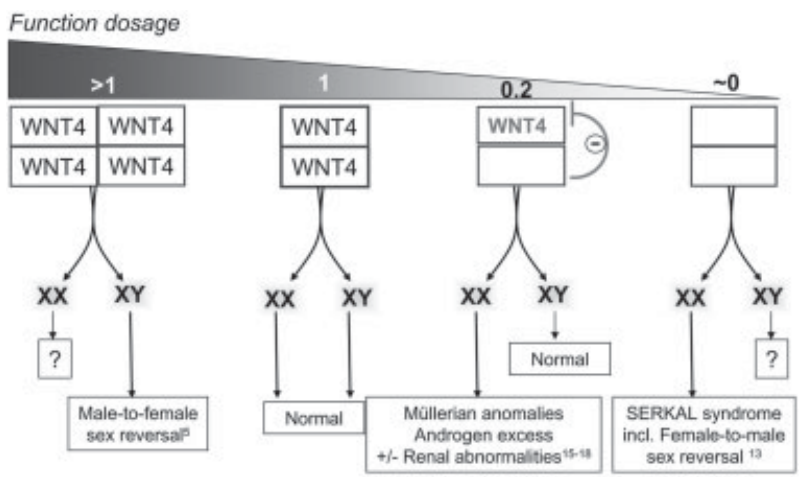

Figure 3 Hypothetical relationship between WNT4 dosage and manifestation of disease. Normal function (and dosage) is set as 1.0. Heterozygote mutations have a dominant negative effect on the wildtype protein (red line) and lower the activity by $20 \%$ instead of the expected $50 \%$. functional steroidogenic cells. These animal models suggest that the ovarian phenotype in Rspo1 - - mice is at least in part because of failing overexpression of Wnt 4 in XX gonads. In contrast, Rspo1 - / - female mice do not show adrenal or uterine abnormalities, as Wnt4 - / - mice do, in agreement to the fact that Rspo1 is not expressed in adrenals or mesonephros, indicating that activation of Wnt4 in these organs is independent of Rspo1 (for review see Chassot et al $(2008)^{21}$ ).

Several lines of evidence demonstrated that RSPO1 synergizes with WNT4 in XX gonads to stabilize $\beta$-catenin. ${ }^{22}$ The comparison of the phenotypes of mice lacking RSPO1 or WNT4 suggests that the RSPO1 regulates and synergizes with WNT4 in the developing gonad, but not in the internal genitalia anlagen or the adrenals (-Table $\mathbf{1}$ ).

\section{RSPO-1 and Human Disease}

The essential role of RSPO1 in human ovarian development was demonstrated by studying individuals with palmoplantar hyperkeratosis with squamous cell carcinoma of skin and 46XX, DSD in whom Parma et al demonstrated mutations in the RSPO1 gene. ${ }^{23}$ The authors concluded that RSPO1 is produced and secreted by fibroblasts and regulates keratinocyte proliferation and differentiation. The presence of "functional" testes in the sex-reversed individuals was confirmed by the absence of Müllerian derivatives and by the masculinization of the internal and external genitalia, presumably induced by functioning Sertoli and Leydig cells, respectively. All sex-reversed individuals were sterile. Notably, the normal reproductive phenotype of $46, \mathrm{XY}$ individuals suggested that normal RSPO1 is not required for testis differentiation and function. 
Table 1 Reproductive Phenotype in 46,XX Knock-Out Mice

\begin{tabular}{|l|l|l|l|}
\hline & Wnt4 & Rspo1 & Possible Mechanism \\
\hline Coelomic vessels & no & no & Failed Wnt4 up-regulation \\
\hline $\begin{array}{l}\text { Leydig-like cells } \\
\text { Androgen-synthesis } \\
\text { enzymes expression) }\end{array}$ & yes & yes & Failed Wnt4 up-regulation \\
\hline $\begin{array}{l}\text { Sertoli-like cells (Sox9 and } \\
\text { Amh expression) }\end{array}$ & yes & yes & Failed Wnt4 up-regulation \\
\hline Germ cells & $\begin{array}{l}\text { Many survive after birth, } \\
\text { but only 20\% enter meiosis }\end{array}$ & Only 10\% survive & $\begin{array}{l}\text { Normal basal (non stimulated) } \\
\text { Wnt4 expression in Rspo1 -/- }\end{array}$ \\
\hline Internal genitalia & No Müllerian deriatives & Hermaphodite & $\begin{array}{l}\text { Wnt4 is expressed in the } \\
\text { mesonephron, Rspo1 is not }\end{array}$ \\
\hline Adrenals & Ectopic vessels & Normal & Wnt4 is expressed in adrenals, Rspo1 is not \\
\hline
\end{tabular}

Derived from references. ${ }^{21,64}$

In a 46, XX SRY-negative woman with true hermaphroditism and palmoplantar keratoderma whose parents were first cousins, in whom no mutations were found in several other gene, including WNT4, Tomaselli et $\mathrm{al}^{24}$ identified homozygosity for a splice site mutation in the RSPO1 gene. The authors stated that this was the first patient in whom $\mathrm{XX}$ true hermaphroditism was associated with a single gene alteration in the absence of SRY.

\section{FOXL2}

FOXL2 is a single-exon gene encoding a forkhead/winged helix transcription factor and a nuclear protein. ${ }^{25}$ In vertebrates, FOXL2 is one of the earliest known markers of ovarian differentiation. ${ }^{26}$ Thus, it may play a role in the early stage of development of the ovarian somatic compartment. As it is still strongly expressed in postnatal and adult follicular cells, it is thought to play a role in follicle development and/or maintenance during fertile life.

Despite the importance of FOXL2 in ovarian development and maintenance, only a few transcriptional targets have been described so far. ${ }^{27,28}$ FOXL2 seems to stimulate the expression of the gonadotropin-releasing hormone receptor. Foxl2 expression precedes glycoprotein hormone $\alpha$-subunit ( $\alpha$-GSU; common subunit to FSH, $\mathrm{LH}$, and TSH) expression in the pituitary, suggesting that the $\alpha$-GSU gene is a downstream target of FOXL2. Indeed, it has been shown that expression of Foxl2 activates the expression of $\alpha$-GSU in cellular and transgenic mice models by a direct effect on the $\alpha$-GSU promoter. ${ }^{29}$ Some data suggest that target specificity could stem from the interactions of Foxl2 with still unknown cofactors expressed in a tissue and/or cell specific manner. ${ }^{30}$ FOXL2 has also been shown to interact directly with the promoter of the steroidogenesis acute response (StAR) gene, to induce a robust inhibition of its basal transcriptional activity. ${ }^{27}$ StAR is a marker of late differentiation of granulosa cells in preovulating follicles and catalyzes cholesterol translocation from the outer to the inner mitochondrial membrane, where it can subsequently be processed in its way to yield pregnenolone and eventually steroid hormones. This translocation of cholesterol is the rate-limiting step in steroidogenesis. The role of FoxL2 in steroidogenesis in the ovary was further strengthened by the fact that it can upregulate the expression of aromatase, the enzyme responsible for the transformation of androgens to estrogens in granulosa cells. ${ }^{28}$

In addition, FOXL2 seems to play a role in the reactive oxygen species detoxification pathways, as several of its members are upregulated by the overexpression of FOXL2, namely peroxisome proliferator-activated receptor gamma coactivator 1-alpha, immediate early response 3 , and the mitochondrial manganese superoxide dismutase genes (Moumné L et al (2008) and references therein). ${ }^{31}$ It is known that an increased resistance to oxidative stress correlates with longevity. ${ }^{32}$ Thus, FOXL2 could play a major role in the regulation of ovarian senescence because its mutation leads to a phenotype similar to an accelerated ovarian aging (see below). FOXL2 also appears to be implicated in the regulation of apoptosis, as it activates the transcription of several genes encoding factors involved in apoptotic processes. ${ }^{33}$ In addition, FOXL2 seems to regulate players of inflammation processes such as several chemokine ligands and especially prostaglandin-endoperoxide synthase 2 (PTGS2)/ cyclooxygenase 2. The latter is one of the two isoforms of cyclooxygenases involved in the synthesis of prostaglandins and catalyses the rate-limiting step of conversion of arachidonic acid into prostaglandin $\mathrm{H} 2$, which is subsequently converted to other prostaglandins by specific synthases. ${ }^{34}$ The fact that FOXL2 strongly activates PTGS2 points to an important role for prostaglandins in ovarian function and lead to the claims that ovulation is an inflammatory-like process and suggests that FOXL2 might act very early during gonadal determination and all the way through the latest stages of follicular maturation and ovulation.

The crucial role of FOXL2 in the life of the ovary has been supported by the seminal work of Uhlenhaut et al, ${ }^{35}$ who by deleting Foxl2 in adult mice ovary, reprogrammed granulosa and theca cells into Sertoli- and Leydig-like cells. This work elegantly shows that the mammalian ovarian phenotype has to be maintained throughout life, mainly by active repression of the male-promoting gene Sox9. 


\section{FOXL2 and Human Disease}

Mutations in FOXL2 are responsible for blepharophimosisptosis-epicanthus inversus syndrome (BPES), which is a genetic disease leading to complex eyelid malformation and other mild craniofacial abnormalities and can present itself with premature ovarian failure (POF) (i.e., BPES I) or without it (BPES II).

In addition, work by Shah et $\mathrm{al}^{36}$ analyzed four adult-type ovarian granulosa-cell tumor (GCT) specimens for GCTspecific mutations and identified a somatic point mutation, (C134W) in the FOXL2 gene in all four specimens. The C134W mutation was present in several other additional GCTs and thecomas, but was absent in sex cord/stromal tumors of other types and unrelated ovarian or breast tumors. The authors concluded that mutant FOXL2 is a potential driver in the pathogenesis of adult-type GCTs.

In search for a molecular mechanism and a genotypephenotype correlation, Moumné et $\mathrm{al}^{37}$ showed that premature stop codons in the FOXL2 gene may lead to the production of N-terminally truncated proteins that strongly aggregated in the nucleus, partially localized in the cytoplasm, and retained a fraction of the wild-type protein. The same authors in a more recent study ${ }^{38}$ noted that polyalanine expansions of +10 residues (i.e., 24 alanines) in FOXL2 have been identified in $~ 30 \%$ of BPES patients and are mainly responsible for BPES type II. Dipietromaria et $\mathrm{al}^{39}$ dissected the molecular and functional effects of 10 FOXL2 mutants, known to induce BPES with or without POF. There was a correlation between the transcriptional activities of FOXL2 variants, suggesting that a FOXL2 mutant completely lacking transactivation activity is likely to lead to BPES with POF. More recently, Benayoun et $\mathrm{al}^{40}$ by using a functional genomic approach found that FOXL2 modulates cell-cycle regu-

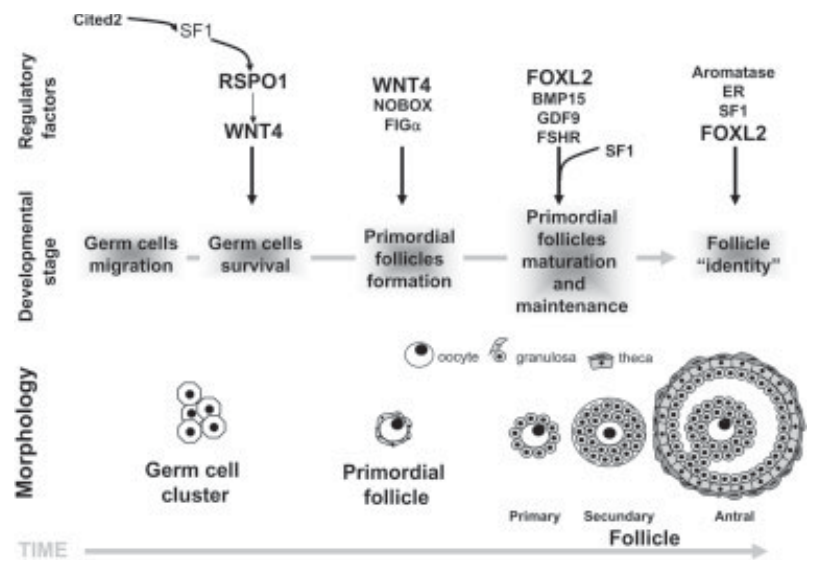

Figure 4 Simplified view of the ovarian germ cell/follicle developmental cascade and the sequence of factors regulating the process. Abbreviations: Cited2, Cbp/P300-Interacting Transactivator $2^{63}$; SF-1, steroidogenic factor 1; Wnt4, wingless-type MMMTV integration site family member 4; RSPO1, R-spondin 1; FOXL2, Forkhead transcription factor; Fig $\alpha$, Factor in Germline $\alpha$; NOBOX, Newborn Ovary. lators in a way that tends to induce G1 arrest and protects cells from oxidative damage. They also demonstrated in agreement with clinical observations that FOXL2 mutants found in BPES with ovarian dysfunction (BPES I) mostly fail to transactivate cell-cycle and DNA-repair targets, whereas mutations leading to isolated craniofacial defects (and normal ovarian function, BPES II) activate them correctly. Sirtuin 1 deacetylase appears to play a key role in this process by suppressing FOXL2 activity on targets linked to cell-cycle and DNA repair in a dose-dependent manner. This evidence supports the idea that FOXL2 plays a key role in granulosa cell homeostasis, the failure of which is central to ovarian aging and tumorigenesis.

\section{Additional Factors}

These factors, although not directly involved in ovarian determination, are essential for ovarian function and survival.

Two oocyte-specific transcription factors, among others, also play a critical role in oocyte survival: factor in the germline $\alpha^{41}$ and newborn ovary homeoBOX-encoding gene (NOBOX). ${ }^{42}$ Absence of these genes results in oocyte death and prevents the subsequent formation of primordial follicles because of a failure of the ovigerous cords to become follicles. ${ }^{43}$ Fbxw15/Fbxo12J, an F-box containing gene specifically expressed in mouse ovary, was recently shown to possibly contribute to ovarian physiology by preventing oocytes from exiting meiotic prophase or by regulating signaling events required for oocyte-granulosa cell communication. ${ }^{44}$ Bone morphogenic protein 15 (BMP15) and growth differentiation factor 9 (GDF9) are crucial for ovarian follicle physiology, probably by controlling its metabolism. $^{45}$ In women, BMP15 and NOBOX mutations have

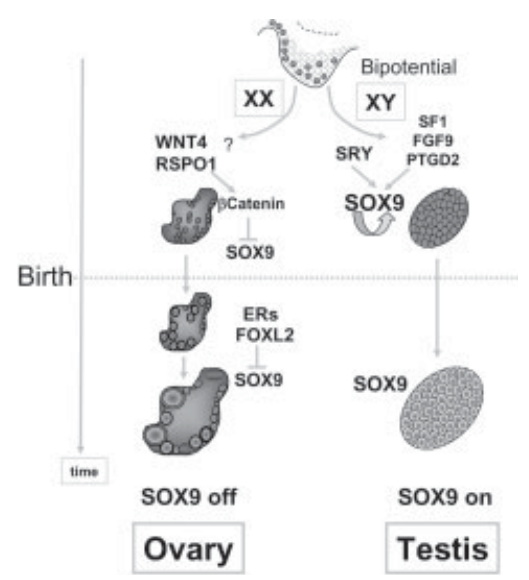

Figure 5 Simplified model of sex development cascade. In early stages of determination, SRY in XY subjects initiates SOX9 upregulation, which is then maintained by SOX9 itself, SF1, PTGD2, and FGF9. In the XX gonad WNT4/RSPO1 stabilize $\beta$-catenin that, in turn, suppresses SOX9. After birth, FOXL2 with the help of the ERs maintains the transcriptional repression of SOX9, which is necessary to preserve ovarian function throughout life. Abbreviations: ERs, estrogen receptors; FOXL2, forkhead transcription factor; FGF9, fibroblast growth factor 9; PTGD2, prostaglandin D2; RSPO1, R-spondin 1; SF1, steroidogenic factor 1; SOX9, SRY-box 9; WNT4, wingless-type MMMTV integration site family member 4 . 


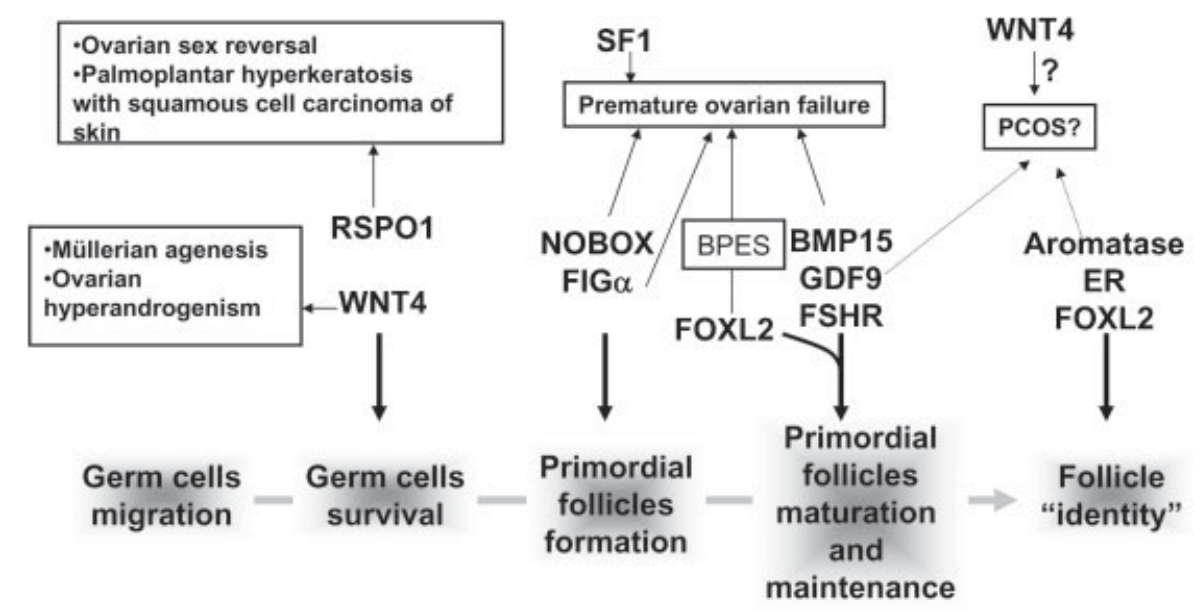

Figure 6 Effect of mutations of regulatory factors in human ovarian function. Abbreviations: SF-1, steroidogenic factor 1; Wnt4, winglass-type MMTV integration site family member 4; RSPO1, R-spondin 1; FOXL2, Forkhead transcription factor; Figa, Factor in Germline alpha; NOBOX, Newborn Ovary HomeoBOX transcription factor; BMP15, Bone Morphogenic Factor 15; GDF9, Growth Differentiation Factor 9; ER, Estrogen Receptor; FSHR, Follicle Stimulating Hormone Receptor.

been associated with $\mathrm{POF}^{46-48}$ whereas GDF9 aberrant expression and genomic variants have been linked to premature ovarian insufficiency and twin pregnancy, respectively. ${ }^{49-52}$ Maintenance of follicle "identity" is guaranteed by estrogen formation and action, as demonstrated by the transdifferentiation of normally formed ovarian tissue into testicular structures in mice lacking enzyme aromatase (converting androgens to estrogens) ${ }^{53}$ and/or estrogen receptor. ${ }^{54,55}$ Human steroidogenic factor-1 (SF1/NR5A1) is a 461 amino acid protein that shares structural homology with other members of the nuclear receptor superfamily essential for the developing adrenals and male gonad. In 46, $\mathrm{XY}$ individuals, mutation in the human SF1/NR5A1 gene has a phenotypic spectrum that ranges from complete testicular dysgenesis with Müllerian structures, through individuals with mild clitoromegaly or genital ambiguity, to severe penoscrotal hypospadias or even anorchia. ${ }^{56}$ In females, persistent expression of SF1 has been reported in early ovarian development in humans, ${ }^{57}$ whereas SF1 expression may decline in the mouse. However, SF1 is detectable in somatic cells (granulosa and theca cells) of the adult ovary. ${ }^{58}$ Although SF1 is not required for ovarian determination, ${ }^{59}$ heterozygote mutations in NR5A1 have recently been linked to ovarian insufficiency. ${ }^{60}$

\section{Conclusions}

The idea that the female sexual development is passive and happens by default was based on the fact that the female reproductive tract develops even in the absence of any gonad.

Recent advances demonstrated that ovarian development and maintenance are active processes. In fact, WNT4 synergizes with RSPO1 to stabilize $\beta$-catenin that, in turn, suppresses expression of the male-specific gene SOX9. ${ }^{35}$ As a consequence migration of mesonephric endothelial and steroidogenic cells, formation of male-specific coelomic blood vessels and production of steroids are prevented, ${ }^{7,61}$ with an overall "antitestis" effect. WNT4, RSPO1, and FOXL2 also work as "pro-ovary" factors, with WNT4/RSPO1 being necessary for early somatic cell differentiation and for protection of the germ cells in mice ${ }^{6}$ and in humans, ${ }^{17}$ while FOXL2 is essential for follicle formation and identity ${ }^{21}$ (-Fig. 4). These factors work in concert but at different time points: during determination in utero, the process is led by the WNT4/ RSPO1/ $\beta$-catenin pathway; after birth and throughout life, FOXL2 (and the estrogen receptors) are the major regulators. Thus, it appears that while male sex determination is regulated by a single pathway of SOX9 activation, the female ovarian development is controlled by at least two ways of SOX9 suppression (-Fig. 5).

From a more clinical point of view, mutations in these factors have consequences not only for ovarian ontogeny and sex development but their interactions are necessary throughout the lifetime of the female to prevent ovarian dysfunction, including infertility, premature ovarian insufficiency, and perhaps polycystic ovary syndrome (-Fig. 6).

\section{References}

1 McElreavey K, Vilain E, Abbas N, Herskowitz I, Fellous M. A regulatory cascade hypothesis for mammalian sex determination: SRY represses a negative regulator of male development. Proc Natl Acad Sci USA 1993;90(8):3368-3372

2 He X, Semenov M, Tamai K, Zeng X. LDL receptor-related proteins 5 and 6 in Wnt/beta-catenin signaling: arrows point the way. Development 2004;131(8):1663-1677

3 Nusse R. Wnts and Hedgehogs: lipid-modified proteins and similarities in signaling mechanisms at the cell surface. Development 2003;130(22):5297-5305

4 Pandur P, Läsche M, Eisenberg LM, Kühl M. Wnt-11 activation of a non-canonical Wnt signalling pathway is required for cardiogenesis. Nature 2002;418(6898):636-641

5 Jääskeläinen M, Prunskaite-Hyyryläinen R, Naillat F, et al. WNT4 is expressed in human fetal and adult ovaries and its signaling contributes to ovarian cell survival. Mol Cell Endocrinol 2010;317(1-2):106-111 
6 Jordan BK, Mohammed M, Ching ST, et al. Up-regulation of WNT-4 signaling and dosage-sensitive sex reversal in humans. Am J Hum Genet 2001;68(5):1102-1109

7 Vainio S, Heikkilä M, Kispert A, Chin N, McMahon AP. Female development in mammals is regulated by Wnt-4 signalling. Nature 1999;397(6718):405-409

8 Yao HH, Matzuk MM, Jorgez CJ, et al. Follistatin operates downstream of Wnt4 in mammalian ovary organogenesis. Dev Dyn 2004;230(2):210-215

9 Merchant H. Rat gonadal and ovarioan organogenesis with and without germ cells. An ultrastructural study. Dev Biol 1975;44 (1):1-21

10 McLaren A. Meiosis and differentiation of mouse germ cells. Symp Soc Exp Biol 1984;38:7-23

11 Naillat F, Prunskaite-Hyyryläinen R, Pietilä I, et al. Wnt4/5a signalling coordinates cell adhesion and entry into meiosis during presumptive ovarian follicle development. Hum Mol Genet 2010;19(8):1539-1550

12 Ottolenghi C, Pelosi E, Tran J, et al. Loss of Wnt4 and Foxl2 leads to female-to-male sex reversal extending to germ cells. Hum Mol Genet 2007;16(23):2795-2804

13 Mandel H, Shemer R, Borochowitz ZU, et al. SERKAL syndrome: an autosomal-recessive disorder caused by a loss-of-function mutation in WNT4. Am J Hum Genet 2008;82(1):39-47

14 Domenice S, Corrêa RV, Costa EM, et al. Mutations in the SRY, DAX1, SF1 and WNT4 genes in Brazilian sex-reversed patients. Braz J Med Biol Res 2004;37(1):145-150

15 Biason-Lauber A, Konrad D, Navratil F, Schoenle EJA. A WNT4 mutation associated with Müllerian-duct regression and virilization in a 46,XX woman. N Engl J Med 2004;351(8):792- 798

16 Biason-Lauber A, De Filippo G, Konrad D, Scarano G, Nazzaro A, Schoenle EJ. WNT4 deficiency-a clinical phenotype distinct from the classic Mayer-Rokitansky-Kuster-Hauser syndrome: a case report. Hum Reprod 2007;22(1):224-229

17 Philibert P, Biason-Lauber A, Rouzier R, et al. Identification and functional analysis of a new WNT4 gene mutation among 28 adolescent girls with primary amenorrhea and müllerian duct abnormalities: a French collaborative study. J Clin Endocrinol Metab 2008;93(3):895-900

18 Philibert P, Biason-Lauber A, Gueorguieva I, et al. Molecular analysis of WNT4 gene in four adolescent girls with mullerian duct abnormality and hyperandrogenism (atypical Mayer-Rokitansky-KüsterHauser syndrome). Fertil Steril 2011;95(8):2683-2686

19 Kamata T, Katsube K, Michikawa M, Yamada M, Takada S, Mizusawa H. R-spondin, a novel gene with thrombospondin type 1 domain, was expressed in the dorsal neural tube and affected in Wnts mutants. Biochim Biophys Acta 2004;1676 (1):51-62

20 Kim KA, Kakitani M, Zhao J, et al. Mitogenic influence of human Rspondin1 on the intestinal epithelium. Science 2005;309 (5738):1256-1259

21 Chassot AA, Gregoire EP, Magliano M, Lavery R, Chaboissier MC. Genetics of ovarian differentiation: Rspo1, a major player. Sex Dev 2008;2(4-5):219-227

22 Chassot AA, Ranc F, Gregoire EP, et al. Activation of beta-catenin signaling by Rspo1 controls differentiation of the mammalian ovary. Hum Mol Genet 2008;17(9):1264-1277

23 Parma P, Radi O, Vidal V, et al. R-spondin1 is essential in sex determination, skin differentiation and malignancy. Nat Genet 2006;38(11):1304-1309

24 Tomaselli S, Megiorni F, De Bernardo C, et al. Syndromic true hermaphroditism due to an R-spondin1 (RSPO1) homozygous mutation. Hum Mutat 2008;29(2):220-226

25 Crisponi L, Deiana M, Loi A, et al. The putative forkhead transcription factor FOXL2 is mutated in blepharophimosis/ptosis/epicanthus inversus syndrome. Nat Genet 2001;27(2):159-166

26 Cocquet J, Pailhoux E, Jaubert F, et al. Evolution and expression of FOXL2. J Med Genet 2002;39(12):916-921
27 Pisarska MD, Bae J, Klein C, Hsueh AJ. Forkhead 12 is expressed in the ovary and represses the promoter activity of the steroidogenic acute regulatory gene. Endocrinology 2004;145(7): 3424-3433

28 Pannetier M, Fabre S, Batista F, et al. FOXL2 activates P450 aromatase gene transcription: towards a better characterization of the early steps of mammalian ovarian development. J Mol Endocrinol 2006;36(3):399-413

29 Ellsworth BS, Egashira N, Haller JL, et al. FOXL2 in the pituitary: molecular, genetic, and developmental analysis. Mol Endocrinol 2006;20(11):2796-2805

30 Pannetier M, Renault L, Jolivet G, Cotinot C, Pailhoux E. Ovarianspecific expression of a new gene regulated by the goat PIS region and transcribed by a FOXL2 bidirectional promoter. Genomics 2005;85(6):715-726

31 Moumné L, Batista F, Benayoun BA, et al. The mutations and potential targets of the forkhead transcription factor FOXL2. Mol Cell Endocrinol 2008;282(1-2):2-11

32 Henderson ST, Johnson TE. daf-16 integrates developmental and environmental inputs to mediate aging in the nematode Caenorhabditis elegans. Curr Biol 2001;11(24):1975-1980

33 Batista F, Vaiman D, Dausset J, Fellous M, Veitia RA. Potential targets of FOXL2, a transcription factor involved in craniofacial and follicular development, identified by transcriptomics. Proc Natl Acad Sci U S A 2007;104(9):3330-3335

34 Smith WL, Dewitt DL. Prostaglandin endoperoxide H synthases-1 and -2. Adv Immunol 1996;62:167-215

35 Uhlenhaut NH, Jakob S, Anlag K, et al. Somatic sex reprogramming of adult ovaries to testes by FOXL2 ablation. Cell 2009;139 (6):1130-1142

36 Shah SP, Köbel M, Senz J, et al. Mutation of FOXL2 in granulosa-cell tumors of the ovary. N Engl J Med 2009;360(26):2719-2729

37 Moumné L, Fellous M, Veitia RA. Deletions in the polyAlaninecontaining transcription factor FOXL2 lead to intranuclear aggregation. Hum Mol Genet 2005;14(23):3557-3564

38 Moumné L, Dipietromaria A, Batista F, et al. Differential aggregation and functional impairment induced by polyalanine expansions in FOXL2, a transcription factor involved in cranio-facial and ovarian development. Hum Mol Genet 2008;17(7):1010-1019

39 Dipietromaria A, Benayoun BA, Todeschini AL, Rivals I, Bazin C, Veitia RA. Towards a functional classification of pathogenic FOXL2 mutations using transactivation reporter systems. Hum Mol Genet 2009;18(17):3324-3333

40 Benayoun BA, Georges AB, L'Hôte D, et al. Transcription factor FOXL2 protects granulosa cells from stress and delays cell cycle: role of its regulation by the SIRT1 deacetylase. Hum Mol Genet 2011;20(9):1673-1686

41 Liang L, Soyal SM, Dean J. FIGalpha, a germ cell specific transcription factor involved in the coordinate expression of the zona pellucida genes. Development 1997;124(24):4939-4947

42 Rajkovic A, Pangas SA, Ballow D, Suzumori N, Matzuk MM. NOBOX deficiency disrupts early folliculogenesis and oocyte-specific gene expression. Science 2004;305(5687):1157-1159

43 Soyal SM, Amleh A, Dean J. FIGalpha, a germ cell-specific transcription factor required for ovarian follicle formation. Development 2000;127(21):4645-4654

44 De La Chesnaye E, Kerr B, Paredes A, Merchant-Larios H, Méndez JP, Ojeda SR. Fbxw15/Fbxo12J is an F-box protein-encoding gene selectively expressed in oocytes of the mouse ovary. Biol Reprod 2008;78(4):714-725

45 Su YQ Sugiura K, Wigglesworth K, et al. Oocyte regulation of metabolic cooperativity between mouse cumulus cells and oocytes: BMP15 and GDF9 control cholesterol biosynthesis in cumulus cells. Development 2008;135(1):111-121

46 Di Pasquale E, Rossetti R, Marozzi A, et al. Identification of new variants of human BMP15 gene in a large cohort of women with premature ovarian failure. J Clin Endocrinol Metab 2006;91(5): 1976-1979 
47 Dixit H, Rao LK, Padmalatha VV, et al. Missense mutations in the BMP15 gene are associated with ovarian failure. Hum Genet 2006;119(4):408-415

48 Qin Y, Choi Y, Zhao H, Simpson JL, Chen ZJ, Rajkovic A. NOBOX homeobox mutation causes premature ovarian failure. Am J Hum Genet 2007;81(3):576-581

49 Palmer JS, Zhao ZZ, Hoekstra C, et al. Novel variants in growth differentiation factor 9 in mothers of dizygotic twins. J Clin Endocrinol Metab 2006;91(11):4713-4716

50 Chand AL, Ponnampalam AP, Harris SE, Winship IM, Shelling AN. Mutational analysis of BMP15 and GDF9 as candidate genes for premature ovarian failure. Fertil Steril 2006;86(4):1009-1012

51 Kovanci E, Rohozinski J, Simpson JL, Heard MJ, Bishop CE, Carson SA. Growth differentiating factor-9 mutations may be associated with premature ovarian failure. Fertil Steril 2007;87(1): 143-146

52 Harris SE, Chand AL, Winship IM, Gersak K, Aittomäki K, Shelling AN. Identification of novel mutations in FOXL2 associated with premature ovarian failure. Mol Hum Reprod 2002;8(8):729-733

53 Britt KL, Findlay JK. Regulation of the phenotype of ovarian somatic cells by estrogen. Mol Cell Endocrinol 2003;202(1-2):11-17

54 Couse JF, Hewitt SC, Bunch DO, et al. Postnatal sex reversal of the ovaries in mice lacking estrogen receptors alpha and beta. Science 1999;286(5448):2328-2331

55 Dupont S, Krust A, Gansmuller A, Dierich A, Chambon P, Mark M. Effect of single and compound knockouts of estrogen receptors alpha (ERalpha) and beta (ERbeta) on mouse reproductive phenotypes. Development 2000;127(19):4277-4291
56 Lin L, Achermann JC. Steroidogenic factor-1 (SF-1, Ad4BP, NR5A1) and disorders of testis development. Sex Dev 2008;2(4-5): 200-209

57 Hanley NA, Ball SG, Clement-Jones M, et al. Expression of steroidogenic factor 1 and Wilms' tumour 1 during early human gonadal development and sex determination. Mech Dev 1999; 87(1-2):175-180

58 Murayama C, Miyazaki H, Miyamoto A, Shimizu T. Involvement of Ad4BP/SF-1, DAX-1, and COUP-TFII transcription factor on steroid production and luteinization in ovarian theca cells. Mol Cell Biochem 2008;314(1-2):51-58

59 Biason-Lauber A, Schoenle EJ. Apparently normal ovarian differentiation in a prepubertal girl with transcriptionally inactive steroidogenic factor 1 (NR5A1/SF-1) and adrenocortical insufficiency. Am J Hum Genet 2000;67(6):1563-1568

60 Lourenço D, Brauner R, Lin L, et al. Mutations in NR5A1 associated with ovarian insufficiency. N Engl J Med 2009;360(12):1200-1210

61 Jeays-Ward K, Hoyle C, Brennan J, et al. Endothelial and steroidogenic cell migration are regulated by WNT4 in the developing mammalian gonad. Development 2003;130(16):3663-3670

62 Kocer A, Reichmann J, Best D, Adams IR. Germ cell sex determination in mammals. Mol Hum Reprod 2009;15(4):205-213

63 Combes AN, Spiller CM, Harley VR, et al. Gonadal defects in Cited2mutant mice indicate a role for SF1 in both testis and ovary differentiation. Int J Dev Biol 2010;54(4):683-689

64 Tomizuka K, Horikoshi K, Kitada R, et al. R-spondin1 plays an essential role in ovarian development through positively regulating Wnt-4 signaling. Hum Mol Genet 2008;17(9):1278-1291 